821.163.41.09-2 Христић J.

821.163.41.09-2 Павловић М.

\title{
MITSKI OBRAZAC U DRAMAMA KAO INTERTEKSTUALNI POLIGON ZA REFLEKSIVNO VIŠEGLASJE: JOVAN HRISTIĆ I MIODRAG PAVLOVIĆ
}

SNEŽANA KESI'́ ${ }^{1}$

Filozofski fakultet, Novi Sad, Srbija

Ovaj rad ispituje intertekstualno posredovanje implementacije antičkog, mitskog u dramama Jovana Hristića i Miodraga Pavlovića u dešifrovanju njihove umetničke recepcije u etičkom i društvenom diskursu.

Interesovanje za mitsko se u njihovim dramama dovodi u korelaciju sa antičkim nasleđem u utvrđivanju njihovog nastojanja za jezikom konstruktivnog prema stvarnosti u prevazi obesmišljavajućeg. U opoziciji sa savremenim postulatima relativizovanog i fragmentarnog, ali u empirijskim kodovima depatetizovanog analizira se iskošeni, ironizovaniokvir stvarnosti seriozne recepcijedramskih pisaca u hodočasništvu za "najdaljim i najdubljim". Mitsko se u njihovoj teorijskoj formuli odslikava u aktuelnom u ravni životnosti inicirajući nužnost stvaranja živog stvaralačkog tkiva oslobođenog dominacije filozofskog i emocionalne beživotnosti. Međutim, privlačnost nesputanosti igre, prokrvljenosti životnog, koje su u teoriji pretpostavili obrascima apstrahovanog, u dramskom rukopisu često su i neželjeno izigrane preciznim koordinatama umnog dijagnostikovanja, tako da se drame ponekad poimaju sa umanjenim ulogom mašte.

Inkorporiranjem grčkog mitskog obrasca kao modela za svoje motivske i idejne predloške apostrofira se čovekovo opstajanje u izostavljanju postulata onostranog u empirijski potvrđenoj realnosti kao i dominaciji savremenog mita apsurda, u uspostavljanju autentičnog referencijalnog poligona za duhovno i refleksivno višeglasje.

Ključne reči: mit, intertekst, ironizacija, depatetizovano, konstruktivističko, refleksivnost.

1 Kontakt podaci (Email): skeysneza@yahoo.com 
U autorskim manuskriptima u kojima je duhovnost menzura referencijalnog u enkodiranju identiteta manuskriptora, mitski obrazac seu intertekstualnom posredovanju instrumentalizuje u ispitivanju "najdaljeg i najdubljeg" u ontološkom vrednovanju umetničke i materijalne stvarnosti. Kroz implementacijumita kao formule "visoke svesti o nama samima" (Pavlović 1999: 12) u interakciji elemenata prvobivstva i desakralizovane stvarnosti u njihovim dramama dešifruju se brojnakontemplativna ugranjavanja u ravni estetičkih, etičkih, društveno- političkih značenja. Drama Miodraga Pavlovića Igra bezimenih (1963), kao i drame Jovana Hristića Čiste ruke (1960), Orest (1961), Sedmorica: kako bismo ih danas čitali (1968), iako su u perifernom recepcijskom statusu u odnosu na njihov poetski i prozni stvaralački opus, emanacija su prepoznatljivog duhovnog strujanja,vrednosnogšifrarnika i autentične misaone rečitosti.

Oba dramska pisca pripadaju onoj grupi dramskih pisaca nakon Drugog svetskog rata čiji su „komadi prevashodno intelektualnih nastojanja, čije misaone drame često koriste mit i time proširuju ugao gledanja na stvarnost" (Selenić 1971: 85), za razliku od grupe pisaca koji su, uprkos izvesnim izuzecima, negovali realistički prosede. U modernoj svetskoj književnosti, na ovaj su način (uz pomen najistaknutijih) Žid, Klodel, 0' Nil, Jursenar, Šo, Kokto, Žirodu, Kami, Eliot, Sartr, Anuj višedimenzionalno osvetljavali brojna pitanja u kontekstu aktuelne umetničke i društvene problematike. Rejmond Vilijams naglašavaznačaj moderne interpretacije grčkog, mitskog obrasca kao „prerađivanja dramske tradicije koja je stvorila mnoge drame u kojima se pojavljuju priče iz grčkih drama, kao oblik savremenog izražavanja," (Williams 1979: 249) suprotstavljajući se apsolutističkom ustrojstvu Aristotelove teorijske formule koja se njegovoj recepciji vekovima "ukoštavala” u naizgled nepomerivoj poziciji. (Williams 1966) Teoretičari poput Anđele Beli ukazuju na značaj obogaćivanja klasičnih tema novim tumačenjima, ali i novim motivima u modernoj dramskoj optici, za razliku od kojih Meletinski naglašava opasno dejstvo mitologizacije koja je u njegovoj recepciji bila modernistička pojava usko povezana sa krizom buržoaske kulture identifikovanom kao posledica krize civilizacije uopšte u kojoj je „idealizovanje mita izraz straha pred istorijom." Antički mitovi kao plod "elitnog lietrarnog nasleđa" u recepciji Margaret Alexiou zadržali su svoj značaj kao vitalna platforma u modernom književnom prosedeu za inkorporiranje humora, ironije, parodije i satire. (Alexiou 2002:4) Hristiću i Pavloviću je mitska osnova ("kao sopstveni primer preobražavanja") (Pavlović 1989: 45) poput Kamija i Sartra intelektualni uslov za apstrahovanje lucidnih uverenja u nastojanju za ontološkom potvrdom aksiomatskog i značaja opstajanja arhetipova u modernom, ironijskom diskursu sadašnjice izostavljajući prejake satirične i parodične elemente poput Anuja.

2 Velimir Lukić piše drame sa antičkim mitskim predloškom, dok su se Borislav Mihajlović Mihiz i LJubomir Simović bavili prevashodno motivima srpskog narodnog eposa koji u u svojoj osnovi ima mitske elemente. Uhermetičkim okvirima tadašnjeg društveno- političkog prostora, umetnički govor je inkorporiranjem mita kao posrednog jezikana implicitan način produbljivao recepciju o aktuelnim pitanjima u rascepu između ideološke zadatosti i slobodne umetničke ekspresije.KrajemXX veka pojavili su se mladi autori koji su u reakciji nagrozu ratnih okolnosti opet posegnuli za mitom i antikom, poput Miomira Petrovića (Argivski incident), Boška Milina (Na Grčke kalende), Ivana Panića (Sokratov testament), Gordana Maričića (Brut), Petra Milosavljevića (Tebanci). 
Intertekst u mitskoj implementaciji u Hristićevim i Pavlovićevim dramama u produbljenoj relaciji nadograđuje duhovni integritet originala obogaćujući autentičnom umetničkom recepcijom. ${ }^{3}$ Rolan Bart je ukazujući na značaj intertekstualnosti "kao uslova same tekstualnosti" definisao intertekst "kao jedinu moguću opciju, nemogućnost življenja izvan beskonačnog teksta" inicirajući smrt autora i rođenje čitaoca. Hristić ga parafrazira ukazujući kako je u drami prepoznavanje važnije od upoznavanja, pa su u njoj pozajmice ne samo češće nego u drugim rodovima književnosti, nego su i jedan od načina njenog postojanja. (Hristić 2006: 140)

Vrednujući mit u dijahronijskoj optici Hristić izdvaja imena pesnika Kitsa i Helderlina u doba romantizma kao rodonačelnike recepcije mita slične savremenoj: „On je instrument za istraživanje ljudske sudbine: konstanta u bezbrojnoj raznolikosti života koju vidimo oko sebe. Formula kojom se može izraziti neki smisao za koji verujemo da pisac treba da ga otkriva (...) kao nešto duboko, što leži u nama daleko ispod budne i racionalne svesti. Kao formulu našeg iskustva, koja se pojavi i otkrije u nekim presudnim i prelomnim trenucima." (Hristić 1994: 198- 199) Duhovni punkt mitskog u svom aktancijalnom čvorištu humanističkog i konstruktivnog u svojoj refleksivnoj mnogoznačnosti u Hristićevim i Pavlovićevim dramama otvara prostor za ispitivanje vrednosti u odnosu klasičnog i modernog, metafizičkog i desakralizovanog, apstraktnog i konkretnog, teorije i prakse, estetskog i antiumetničkog, intuitivnog i racionalnog, umetničkog i filozofskog, istorije i filozofije, mita i antimita, sudbine i slobode čovekovog opredeljenja, arhetipskih polova dobra i zla, visoko etičkog i beščašća u primarnom valorizovanju duhovnog i stvaralačkog integriteta.

U serioznoj recepciji u hodočasništvu za "neslućenim dubinama" interesovanje za mitsk0 ${ }^{5}$ je u pomenutim Hristićevim dramama i u Pavlovićevoj drami u korelaciji sa antičkim nasleđem u nastojanju za potvrđivanjem jezika konstruktivnog prema savremenoj stvarnosti sa predznakom obesmišljavajućeg. „Prema našoj stvarnosti stoji stvarnost mita kao večni, neizmenljivi i vanvremenski nacrt tragedije koji mi svojim životom pretvaramo u gotova dela, uramljena vremenom i istorijom, i sa onoliko i samo onoliko varijacija u izgledu i značenju prizora koliko ih dopušta vidljiva i skrivena sadržina mita..." (Pekić 1987: 454)

Dok je Mirča Elijade tvrdio da arhajska mitologija „arhetipova i ponavljanja“ ima ulogu u negiranju nepredviđenih situacija, Klod Levi Stros je naglašavao da su mitovi instrumenti za suzbijanje smrti. Preformulacijom mitskog tkiva Hristić i Pavlović potvrđujući poverenje u nasleđe istorije književnosti i neosporavanje civilizacijskih vrednosti ukazuju uz blagu ironijsku desakralizaciju prvobitnog smisla na savremenu

3 Koncept intertekstualnostinajviše su razradili Rolan Bart, (Le degrezero del'ecriture; Elements de semiologie) Mišel Fuko (L’archeologie du savoir), Julija Kristeva (Semeiotike: recherces pour une semanalyse) analitički problematizujući razliku između čistog eklekticizma od kreativne metode stvaranja dela zasnovanim na postojećim.

4 U strukturalističkoj dramskoj misaonoj postavci prepoznatljiv je aktancijalni model konstituisan prvobitno od strane Gremasa, a potom od An Ibersfeld, kao „skup onih konstanti ili 'dubinskih struktura' što leže ispod promenljive, 'otvorene' površine dela." (Miočinović 1981: 20)

5 „Mit živi od našeg dozivanja, vraća se na ovaj svet kao da njime istorija nije nikad sasvim zagospodarila, donosi nam potvrde najvišeg jemca o postojanju Lepog i Dobrog, Strašnog i Moćnog. Bez nas, njega nema. Bez njega, mi bismo bili nešto treće." (Pavlović 1999: 12) 
dijalektičku sintezu jezika svetlog i tamnog u stvaralačkoj potvrdi erosa života, a ne na njihovu nepomirljivost.

Aktivirajući eruditsku svestranost čitalaca i gledalaca sa akcentom na prosejavanju teksta od površnosti, nepotpunosti, protivurečnosti, svih prolaznih smislova i značenja u Hristićevim i Pavlovićevoj dramama problematizuju se pitanja aktuelna za savremeno doba, kao i vanvremenske dileme u kumulativnom refleksivnom naboju. Mit kao „neobuzdano šarolik"(Elijade 2003: 12) matrica je za brojna promišljanja prepoznatljiva za Hristićev i Pavlovićev duhovni horizont kroz ključno nadahnjivanje stvarnosti verom u pozitivno strujanje njenog krvotoka prema smrti i akcentovanje značaja opstajanja duhovne i moralne čistote kao vrhunskog imperativa.

U problematizovanju dijalektičkog ustrojstva stvarnosti apostrofira se mogućnost rafiniranja individualne i društvene svesti kroz duhovnu rehabilitaciju u negovanju ljubavi kao aksioma života, individualnih nastojanja anuliranja zla, inteligencije u funkciji društvenog aktivizma, beskompromisnog ulaganje u porodicu, stvaralaštvo i kulturu kao esencijalna uporišta. Shodno prevazi emocionalnog uloga nad dominirajućim destruktivnim formulama, u jednoznačno obojenoj liniji bezuslovne Ijubavi Jokaste prema Edipu, Elektre prema Orestu ${ }^{6}$, Antigone prema Eteoklu i Poliniku, vernosti Boginje primarnom principu potvrđuje se značaj negovanja plemenitog koda života. U formuli preispitivanja odnosa fizičke i duhovne lepote u eventualnom prevrednovanju klasičnih i modernih estetičkih postulata afirmiše se klasicistički obrazac antičkog estetičkog ideala oličenog u Edipovoj, Orestovoj lepoti dostojnoj vladara, ${ }^{7}$ Boginjinoj dostojnoj jedne muze. Edipova inteligencija, aко u svojoj čistoti nije praktično potvrdljiva, nesvrsihodna je u poređenju sa Tiresijinom koja se, iako bez etičkog autoriteta, u svojoj funkcionalnosti centrira kao ključna referenca u aktuelnom društvenom sistemu. U obrascu inividualnih nastojanja anuliranja zla, otpora samovolji, idiomu vlasti i svođenju mudrosti na konformizam, ukazuje se na negativan profil samousmerenosti i radikalnosti u podređenosti taštini Polinika i Eteokla koja fiksira tvrdoću njihovog ega u služenju nečasnim demonima. U prostoru manevrisanja najširih vasionskih i čovečanskih sila krucijalno je beskompromisno ulaganje u porodicu kao organsku jedinicu kao i u stvaralaštvo i kulturu. U Edipovoj doslednosti u želji da ne učestvuje u nametnutim mitskim i istorijskim obrascima i da ne "prlja ruke" kao i u komentaru na ideje mitskog Oresta u formuli odustajanja od osvete potcrtava se nastojanje za individualnim odupiranjem prevlasti tamnog aktivizma.

Hristić nastoji da nam ukaže na varijetete izbora u ravni mogućeg uzročnoposledičnog toka u dijalektičkom sklopu univerzuma anulirajući komponentu revolta i nasilja kao glavne društvene prakse. U istoimenoj drami Orest uočava nesvrsishodnost destruktivnog okamenjivanja zleduhog pamćenja u uslovima u kojima kod počinilaca ubistva njegovog oca (Klitemnestre i Egista) njihova životna nesreća (u beznačajnosti i trivijalnosti svakodnevnih obeležja) ima isti balast kao i smrt.

Izglasanost sudbinom likova u antičkim mitovima u podređujućoj ravni svih izbornih parametara prevaže u Hristićevoj drami Sedmorica: kako bismo ih danas

6 "Ljubav pamti čitav život, mržnja samo jedan čin," (Hristić 1970: 54)

7 „Iako je izgnana iz estetike, lepota nije izgnana iz našeg doživljaja umetnostii, i ne možemo poreći dda je jedan od najvažijih utisaka koje umetnost ostavlja u nama neka vrsta lepote." (Hristić 2006: 104) 
čitali dokazujući da je element sudbine nekad nemoguće anulirati kad prevlada teško uništivi mit o vlasti, što za posledicu u ovoj drami ima tragičan kraj, implicitno upućujući i na aktuelni društveno - politički prosede. Eteokle i Polinik učestvuju u razobličavanju humanog, bratskog osećajnog uporišta u egocentričnoj podređenosti imperativima vlasti. Iako se u uvodnom delu drame diskutuje mogućnost odstupanja od mitske matrice i nasleđivanja vlasti (Polinik izjavljuje: „Nisam došao ni da osvajam, ni da prolivam krv. Došao sam zato što sam mislio da je vreme da dođem. Sve ostalo nije važno." (Hristić 1970: 208), dodatno se umrežavajući potencijalnim Eteoklovim ublažavanjem zavisnosti od iste, ubrzo se preinačuje u svoje beskompromisno obličje gde mit vlasti nadjačava esencijalnu krvu sponu. Pojam slobode se u funkciji vlasti predešifruje izjednačavajući se sa beneficijama moći, u obrnutoj srazmeri sa mudrim formulama Bernarda Šoa koji je naglašavao da sloboda znači odgovornost i da je to uglavnom razlog zašto je se ljudi boje. (Shaw 1961: 117)

Demistifikujući Suđaje opisima da su „tako male da se kriju u glavicama luka” (Pavlović 1963: 29), u Pavlovićevoj drami se u ironijskom obrascu dijagnostikuje stvarnost sa suprotne strane sudbinskog ustrojavanja životnih diskursa. Mitsko se u ovoj drami (kao i u njegovoj poeziji i prozi) reflektuje kao „znanje, iskustvo, ideal, duhovnost u modernoj umetnosti koja stvara antisliku svoga društva, onoga što je suprotno ideologiji zajednice." (Goljanin 2010: 65)

U ravni osvetljavanja „antiklasicističkih, antiuzvišenih” mehanizama nove stvarnosti "suše bezimenosti, jezika ulice" (Pavlović 1963: 10) u očuvanju moralnog integriteta stvarnosti ukazuje se na društvene aplikacije i ideološke strategije u očuvanju antropološke osvešćenosti. Predozirano dejstvo vlasti, kao dominantni motiv u Hristićevim dramama Orest i Sedmorica: kako bismo ih danas čitali u sabotaži humanog činodejstvovanja implicira ugao sagledavanja aktuelnih obrazaca vlasti. U sklopu društvenih sila ukomponovanih ujednoumlje učvršćujuće se osećanje potuđenja i emotivna izolacija čoveka u duhovnoj diverziji protiv samog sebe. Prihvatanje dijalektičkog ustrojstva kao jedinog mogućeg profila čovečanstva je u kontekstu apsolutnog podređivanja „bilu moći”, demonu taštine, vlasti i multivantnosti vere saobrazno diktatu aktuelne stvarnosti.

Budući da u aktancijalnom modelu po An Ibersfeld aktant može biti apstrakcija, u slučaju Hristićevih Čistih ruku, to bi upravo bila metafora "čistih ruku" (značaju beskomopromisnog etičkog principa) iz čijeg značenjskog punkta linearno proizilazi ili (ne) proizilazi dalja akcija, kod Oresta odustajanje od osvete u istoj etičkoj postavci, a u Sedmorici: kako bismo ih danas čitali upravo ta osveta kao prevladavajući sindrom u dominaciji mita vlasti. U Pavlovićevoj drami aktancijalno ležište je u pouzdanosti očuvanja osnovnog elementa, bića univerzuma i njegovih vanvremenskih mena u novonastalim duhovnim okvirima. U istraživanju dubljih antropoloških, kulturoloških, povesnih implikacija njegova inspirisanost mitskim sublimira duhovne podsticaje u stalnom stvaralačkom naboju za odupiranjem smrti.

Saglasni u tezi da stvaranje na mitskoj matrici isključuje udaljavanje od života u hermetičnosti „apstrahovanog klasicizma”, svežinom lucidnosti, visprenom ironijom, jezikom inventivnosti, u kodu "usvakodnevljavanja“, u Hristićevim i Pavlovićevim dramama ovaploćuje se suprotstavljanje okoštalim propozicijama tradicionalnog klasicizma. U Pavlovićevoj drami Horovođa izjavljuje: „Nemoj da govorišu dvanaestercu, 
molim te, to ne sme da nam se potkrade." (Pavlović 1963: 8) Dijalozima likova u drami, Prologa, Horovođe, Suđaja, Seni Odiseja, Boginje dramski pisac je pretpostavio značaj očuvanja supstancijalnog užlebljenja stvarnosti i etičke kodiranosti nastojanjima postmodernih savremenih teza da isključe sponu tradicionalnog dramskog nasleđa i klasičnih vrednosti sa ovovremenim, dekonstruisanim („,rekli smo da se o prijateljstvu takođe ne govori. I ono spada u dramske odnose, sećaš se; Orest i Pilad, i tako dalje, a mi to hoćemo da izbegnemo (...) sve te helenske priče su mi dosadile... i erotičke."(Pavlović 1963: 44) Problematizujući status ključnih duhovnih vrednosti u svojim matičnim odnosima (poput rodbinskih i prijateljskih) u dominirajućem savremenom obrascu relativizovanog, Pavlović upućuje i na devalorizovanje erotičkog kao esencijalnog pulsa života u izvoru stvaralaštva što je više puta naznačio. ${ }^{8}$

Brojne klasicističke odlike Hristićevh drama poput aluzivnosti prevashodno usmerene na antiku, čistote u izvođenju, mudrosti u jednostavnosti, uzdržanosti u emocijama, ravnoteže između čulnog, odnosno emotivnog i intelektualnog esencijalno su utkane u prepoznatljive koordinate modernog (iskošeni, ironizovani okvir). U kompozicionoj linearnosti Hristićevih drama u dramskom ritmu bez oscilacija i naglih preokreta rasplet se naslućuje na početku drama. ${ }^{9}$ Kroz jezgrovite, jasne, pronicljive i duboko promišljene refleksije isključene su kontinuirane tenzije i nepredvidivi obrti nepouzdanog anarhičnog obrasca ukazujući na jezik u koordinatama modernog klasicizma koji ne identifikuje visoka estetizovanost, metaforična ushitljivost, punokrvnost oneobičavanja. U dijalozima refleksivne punoće govor likova se ne prekida proizvoljnim segmentima izostavljajući obrazac emocionalnih i čulnih ekstatičnosti čak i u psihološki najzahtevnijem odnosu Klitemnestre i Oresta. Isključujući slike nasilja iz antičkih drama u predominaciji ekstremnih emocionalnih stanja mržnje Hristić osvetljava misaona i emocionalna previranja u ličnosti Oresta u klasicističkom obrascu odmerenosti. Nijansirajući odnos braće Eteokla i Polinika baziran na njihovom odnosu prema vlasti on ukida mesto ratničkim strategijama i dramskoj žestini sukoba. Izostavljanjem tradicionalnih sredstava u klasicističkoj funkciji izazivanja katarzičnog preobražaja (tragične krivice u Čistim rukama i Orestu) piččeva duhovna svest (neobojena sklonošću ka delirijumu ponora ili ekstazi strasti) u obrascu židovske mirnoće, prevagom razumskog poput Pirandela duboko uslojenom moralnom konzistentnošću potvrđuje značaj ustrajavanja koda plemenitosti.

U opoziciji sa savremenim postulatima relativizovanog i fragmentarnog, ali u empirijskim kodovima depatetizovanog, Hristić i Pavlović su profilisali likove subjektiviziranjem njihovih akcija u izostavljajanju balasta mistifikovanja sudbinskog. Mitsko se u njihovoj teorijskoj formuli odslikava u aktuelnom u ravni životnosti inicirajući nužnost stvaranja živog stvaralačkog tkiva oslobođenog dominacije filozofskog i emocionalne beživotnosti, kako bi Horovođa u Pavlovićevoj drami izjavio: „Bojim se da ne postanemo simboli (...) ja nikada nisam mislio da se od filozofije može napraviti dobar pozorišni komad." (Pavlović 1963: 62) U njihovoj recepciji život, kao

8 „Stvaralaštvo je na početku i na kraju poetičnog života: i mit je nekada morao biti poetično stvoren, i obred zamišljen i opravdan. Erotični princip je u stvaralaštvu sadržan, kao što je stvaralaštvo u samom jezgru erotizma." (Pavlović 1998: 19)

9 Izuzetak je u Sedmorici: kako bismo ih danas čitali gde uvertira ima drugačiji tok, ali je u obrascu odmerenosti isključena nagla promena diskursa. 
ni umetnost nemaju predznak heroizma, vanmaterijalnih i vanvremenskih dostignuća, nego se usaglašavaju prema svojim umerenim mogućnostima, potvrđujući se u sebi samom: „Nema goreg načina da se filozofija umeša u književnost nego da se u jednom književnom delu vidi ilustracija gotovih apstraktnih ideja, pogotovo ideja koje same po sebi više prikrivaju prava pitanja, nego otkrivaju." (Hristić 2006: 98)

Međutim, iako se u ovim dramama ocrtavaju dramski identiteti u punoći sopstvenih težnji i produbljivanju čovekovih mena, preovlađuje refleksivna punoćau njihovojznačenjskoj ravni. Privlačnost nesputanosti igre, prokrvljenosti životnog, koje su Hristić i Pavlović u teoriji pretpostavili obrascima apstrahovanog, u stvaralačkom rukopisu često suineželjeno izigrane preciznim koordinatama umnog dijagnostikovanja, tako da se drame ponekad poimaju sa umanjenim ulogom mašte.

Odnos herojstva i antiherojstva se u književnoj istoriji, premeren uvek novim procenama, reflektuje u akcijama likova Hristićevih i Pavlovićevih drama u pokretanju pitanja o mogućnosti jedinki da se odupru htenjima i potrebama društva, zajednice, mitskoj veličini i njegovoj suprematiji. Hristićevo dramsko delo leži u prepoznavanju čina antiherojstva (u slučaju Edipa i Oresta humanog), potvrđujući herojstvo iluzornom kategorijom u odnosu na biće antiherojstva koje diše na pozornici mesom konkretnog, a ne etrom apstrakcija. „Bilo da se oslanja na mit ili istoriju, Hristić održava jedan dosledan ugao posmatranja. A to je oslobađanje i jednog i drugog od ukrasa, oreola, heroizma, nadljudskog i isticanje običnog, jednostavnog, čovečnog, na način koji dokazuje da i u ovim aspektima ljudskog postojanja postoje neiscrpna bogatstva, neiscrpne mogućnosti za dramu." (Frajnd 1971: 356) Hristićje klasični tekst oživeo u svežini autentičnog humora skicirajući čoveka u konceptu svoje depatetizovane pojave i antiherojstva, u svojoj jednostavnosti i običnosti, akcentujujući jezik samog čina oživotvorenja i čovečnosti u obesmišljavanju uzvišenosti mitova iz humanističke perspektive. Odgonetanjem iskustva zemaljskog života u rasponu od rađanja do umiranja, jedino se izvesnim potvrđuje da svemoć ne postoji, da je onostrano u funkciji zemaljskog, a da je besmrtna ljudska grešna priroda, u rastu i opadanju, u smrti i uskrsnuću konstanta.

Ne tonući u zone zračenja pesimizma i apsurda, kritička svest o dihotomijskoj šifriranosti aktuelnog (,ti nanosi naših vrednosti, to ti jedna istorijska gomila naših protivrečnosti" (Pavlović 1963: 15) ne isključuje obrasce životne raznobojnosti i višeobraznosti. Duhovnu platformu stvaralačkih rukopisa ovih dramskih pisaca identifikuje prevođenje refleksivnog jezika na ideju o mogućnostima metamorfoze čoveka kroz veru u njegova esencijalna uporišta kojim se uprkos prisutnim sumnjama neutrališe dominacija dekonstruktivnog i uspostavlja ritam mogućnosti. Piščeva kontinuirana nastojanja da se u duhovnom vibriranju stvarnosti između aktuelnih rituala katastrofe i mitova apokalipse ${ }^{10}$ izoluje preovlađujući diskurs subverzivnosti apostrofiraju raznorodnost čovekovih mogućnosti u višeličju života i neprekinutom dijalektičkom strujanju. Hristić kroz likove Edipa i Oresta u njihovoj etičkoj ispravnosti poručuje da se individualnim činodejstvovanjem utiče na sučeljavanje sa incidentnom stvarnosti i kreiranju oplemenjenog profila čovečanstva. Ulogama Prologa i Horovođe

10 U dijalogu Prologa i Horovođe u obrascima apsurda: „Svaki grad koji smo videli preko desnog ramena goreo je. Kako onda da znamo odakle smo došli? (...) i taj jezik kojim govorimo, zar on sam zna kako se zove?" (Pavlović 1963:18) 
u njihovoj antitezi Pavlović potcrtava da je svaka potencijlna negacija u liku apsurda u stvari imanentna težnja za svojom afirmacijom i očuvanjem pouzdanog i stabilnog oslonca.

U diktatu razglobljavanja klasičnih teza u desakralizaciji uzvišenog karaktera umetnosti kao „svetom izrazu posvećenih" („Stara je stvar da pesnici mnogo lažu. (...) Naše ćutanje nije nikakvo 'rečito` ćutanje, nikakav vrhovni izraz umetnosti, kako se to danas govori, nego mi prosto nemamo višešta dakažemo"(Pavlović 1963:62), unjihovoj recepciji se ne poništava poverenje u nepovredivost duhovnosti, učvršćujući potrebu za očuvanjem pouzdanosti estetičkih i etičkih vrednosti. U naponu preovlađujućih formula civilizacijske limitiranosti pojam o beskonačnosti nije marginalizovan do svog poricanja. Otvarajući se ka "opštem" $i$ „univerzalnom" u posredovanju mitskog inicira se konstituisanje egzistencije sa predznakom betvremenskog u čijem kontekstu Odisej eksplicira svoju ideju „svuda je beskonačnost. Je l’ ti jasno? Iznad nas, ispred nas, iza nas." (Pavlović 1963: 57) kao odgovor na formule omeđene stvarnosti.

Posredstvom mitskog, u veštom i lakom Hristićevom i Pavlovićevom pisanju se implementira misao o čovekovom najelementarnijem slojevito produbljujući odnose i situacije u nastojanju da se utvrdi specifičnost interakcije između individualnog i društvenog, i stvarnosnog i univerzalnog. Potcrtavanjem značaja čovekoljublja i plemenitijeg ustrojstva na telu grubih sila sveta koji nikad nije samo zao, već ima i svoju svetliju stranu, ukazuje se na mogućnost preoblikovanja stvarnosti u odabiru koji može biti manje tragičan, isključujući nužnost prevlasti tamne semantike i besmisla. Hristićevo i Pavlovićevo obogaćivanje mita iz humanističke perspektive oponira raskrinkavanju i obesmišljavanju stvarnosti kroz apokaliptični sadržaj, destrukciju i ponovno stvaranje pozorišta sa likovima koji predstavljaju silazak u pakao, bez nade za ponovnim uzdizanjem karakterišući mitologiju pozorišta XX veka. Edipovo insistiranje na sopstvenoj čistoti kao i Orestovo na nesprovođenju osvete presudno je uticalo da se izbegne jedna od najstrašnijih ljudskih sudbina koje se mogu zamisliti, jer tragedije razmera porodičnog ubistva izglobljuju ličnosti društvo iz svojih temelja sa posledicama koje se reflektuju u svim krucijalnim aspektima. Boginjino naglašavanje "mogućnosti lepog" i „borbe za vrednost čoveka" Seni u Pavlovićevoj drami i u ravni „bezimenosti" ukazuje na značaj prihvatanja svetlijeg pola dominirajućih dekonstruktivnih obrazaca.

U cilju preoblikovanja postojećih veza između klasičnih motiva u savremenoj drami i publike, promena mitskog tkiva kod ovih dramskih pisaca se ne identifikuje izgonom iz istog, već implementiranjem suptilno ironizirjućih elemenata realizujući dramski diskurs sa demistifikujuće pozicije savremene determinisanosti.

Oba dramska pisca su saglasna u tezi da se civilizacijski i kulturološki identitet primarno potvrđuje u konstruktivističkom valorizivanju aksiomatskog u uverenju da postoje postojani parametri u očuvanju duhovnog integriteta drame i pozorišta u uslovima estetičkog pluralizma. Posredne relacije u umetnosti su često ubedljivije od neposrednih i zato su Hristić i Pavlović antičke obrasce implicitno doveli u vezu sa savremenim, osvetljavajući njeno jezgro u funkciji metaforske potke za razobličavanje sadašnjice. Inkorporiranjem grčkog mitskog obrasca kao modela za svoje motivske i idejne predloške apostrofira se čovekovo opstajanje u izostavljanju postulata onostranog u empirijski potvrđenoj realnosti kao i dominaciji savremenog mita apsurda, u uspostavljanju autentičnog referencijalnog poligona za duhovno i refleksivno višeglasje. 


\section{LITERATURA}

Alexiou,M. 2002. After antiquity : Greek language, myth and metaphor. London: Cornell University Press.

Belli, A. 1969. Ancient Greek Myths and Modern Drama, A Study in Continuity. New York: New York University Press.

Елијаде, М. 2003. Свето и профано. Сремски Карловци, Нови Сад: Издавачка књижарница Зорана Стојановића.

Frajnd, M. 1971. Apokrifi Jovana Hristića. Književna istorija (339 - 356). Broj 14. Beograd: Izdavačko preduzeće "Vuk Karadžić".

Goljanin, S. 2010. Intertekstualnost i identitet (Antički mit u poeziji Miodraga Pavlovića) Riječ (65-70). God. 16. Sv.3. Rijeka: HFDR.

Highet, G. 1967. The Classical Tradition, Greek and Roman Influences on Western Literature. 0xford: Oxford University Press.

Hristić. 1970. Četiri apokrifa. Novi Sad: Matica srpska.

Hristić. 1994. Eseji. Novi Sad: Matica srpska.

Hristić. 2006. Eseji o drami. Priredila Marta Frajnd. Beograd: Srpska književna zadruga. Levi-Stros, K. 2009. Mit i značenje, prev. Zoran Minderević. Beograd: Službeni glasnik. Meletinski, E. 1983. Poetika mita, prev. Jovan Janićijević. Beograd: Nolit. Miočinović, M. 1981. Moderna teorija drame. Beograd: Nolit.

Pavlović, M. 1963. Igre bezimenih. Beograd: Prosveta.

Pavlović, M. 1999. Svečanosti na platou: obredi poetičkog života. Beograd: Prosveta.

Pekić, B. 1987. U traganju za Eleuzinom iligrađenjeArga. Književnost 3-4. Beograd: Prosveta. Selenić, S. 1971. Dramski pravci XX veka. Beograd: Umetnička akademija.

Shaw, G. B. 1961. Four plays by George Bernard Shaw: with the author's notes. New York: Dell. Vilijams. R. 1979. Drama i mitovi. Drama od Ibzena do Brehta, prev. M. Frajnd. Beograd: Nolit.

Williams, R. 1966. Modern tragedy. London: Chatto and Windus.

\section{SUMMARY}

\section{MYTHICAL PATTERN IN DRAMAS AS INTEREXTUAL PLATFORM FOR REFLEXIVE POLYPHONY}

This article examines intertextual intermediation in implementation of the mithycal in the plays of Jovan Hristic and Miodrag Pavlovic in decoding their artistic, ethical and social reception. The interest in the mythical in their plays is in corelation with antique inheritage with tendency for the confirmation of the language of constructiveness with regard to the reality of meaninglessness. In opposition to the contemporary patterns of relativity and fragmentarity, but in empirical codes of unpathetic antiheroic, the ironical frame is analyzed from the serious perspective of drama writers in their search for "the deepest and the furthest". The mythical in their theoretical formula is reflected in the actuality in the plane of vitality initiaitng the need for creating live artistic text free of the domination of philosophical and emotional inanimation. However, the attractiveness of 
disinhibition of game and bloodstream of vitality which are in theory more valued than the forms of speculation, in their plays are often unwillingly diminished by precise coordinates of mental diagnosing, and consequently the plays are sometimes perceived with the lack of imagination. Including the mythical model for their motive engagament, they opposed the myth - old, antique, based on the postulates of destiny, and modern myth of absurd forming authentic, referential platform for spiritual and reflexive polyphony.

KEYWORDS: myth, intertext, ironisation, unpathetic, constructivistic, reflexivity.

(Originalni naučni rad primljen 17.1.2016; ispravljen 21.3.2016; prihvaćen 31.5.2016) 